\title{
O homem na língua: o dialeto como índice de subjetividade e identidade cultural
}

Daniele dos Santos Lima*

Isabela Rêgo Barros**

\section{Resumo}

A teoria traçada neste trabalho gira em torno do axioma enunciativo de Benveniste (2005, 2006, 2014): enunciação é o colocar em funcionamento a língua por um ato individual de utilização. Com base em uma pesquisa qualitativa do tipo estudo de caso, realizada em duas capitais nordestinas, Recife e Salvador, baseada nas orientações de Cardoso (2010) e nos estudos de Benveniste (2005, 2006), identificamos nuances que permeiam a fala de dois espaços próximos, mas, ao mesmo tempo, com características socioculturais distintas. Nosso objetivo é revelar que a enunciação tem valores semióticos e semânticos, que marcam o sujeito no discurso, destacando o dialeto não apenas como traço linguístico de uma comunidade, mas carregado de sentido para os usuários da língua, que, ao mesmo tempo, reafirma a sua identidade cultural.

Palavras-chave: Enunciação. Forma. Identidade cultural. Sentido. Subjetividade.

\section{Introdução}

O sentido de uma palavra ou expressão linguística traz consigo aspectos subjetivos, uma vez que o entendimento reside no instante em que o locutor interage com o alocutor, ou seja, o sentido de um enunciado está no contexto da ação comunicativa. Além disso, a marca cultural do sujeito, o espaço, o tempo e a pessoa são os itens que definirão o sentido do item lexical usado pelo falante.

$\mathrm{O}$ que dificulta o entendimento de sentido de um item lexical é a pluralida-

\footnotetext{
Mestra em Ciências da Linguagem pela Unicap (2016). Graduada em Letras. Professora da Rede Estadual de Pernambuco e professora executora e tutora da Universidade Federal Rural de Pernambuco (UFRPE). E-mail: danlima02@hotmail.com

** Doutora em Letras pela Universidade Federal da Paraíba (UFPB) (2011). Professora do Programa de Pós-Graduação em Ciências da Linguagem da Universidade Católica de Pernambuco e do departamento de Letras da mesma instituição.E-mail: ibelabarros@gmail.com
} Data de submissão: mar. 2017 - Data de aceite: mar. 2017
http://dx.doi.org/10.5335/rdes.v13i1.6799 
de de significados que as formas adquirem no sintagma da língua no momento da fala. Assim, um item lexical pode ter vários sentidos, a depender daquele que fala, com quem ou para quem fala, quando e como fala. Somado a isso, a cultura em que o falante está inserido, a naturalidade, a faixa etária, o grau de escolaridade e o gênero influenciam o significado de uma palavra, pois tais fatores contribuem na constituição das marcas linguísticas do sujeito.

Quando investigamos os dialetos de duas comunidades distintas como Recife e Salvador, percebemos que os verbos, os sinônimos e as mudanças de classes das palavras indicam as transposições de sentido dos itens lexicais. Para Marques, “[...] as palavras evocam, pela natureza de seu significado, as condições socioculturais dos falantes" (2011, p. 65). Elas relembram sua origem sociocultural.

Torna-se mais fácil o entendimento do enunciado quando localizamos o indivíduo que fala e identificamos sua origem, pois a sua procedência será ponto de referência para que o outro o entenda. Dessa forma, a identidade cultural expõe o sujeito que se encontra marcado na língua ao fazer referência a si e ao seu povo ao utilizar, por exemplo, uma forma dialetal no seu discurso.

Com base nesse pressuposto, partimos da Teoria Enunciativa de Émile Benveniste e propomos discutir os valores semânticos e semióticos da enunciação que marcam o sujeito no discurso, destacando o dialeto não apenas como traço linguístico de uma comunidade, mas carregado de sentido para os usuários da língua e lugar de reafirmação da identidade cultural. Conforme Benveniste, "[...] a língua fornece o instrumento linguístico que assegura o duplo funcionamento subjetivo e referencial do discurso" (2006, p. 101). Além disso, o autor explicita que a língua é uma identidade diante das diversidades individuais. Segundo o linguista, a língua não muda, o que pode mudar são os valores das designações das formas que se multiplicam ou substituem no discurso, na relação intersubjetiva.

\section{Aspectos semânticos e semióticos circunscritos à enunciação}

A enunciação, em seu sentido linguístico, parte da dicotomia língua/fala discutida por Ferdinand de Saussure, ainda que não possa ser totalmente associada a ela. O princípio teórico do axioma benvenistiano da Teoria da Enunciação é explicado pelo próprio Benveniste: “[...] a enunciação é este colocar em funcionamento a língua por um ato individual de utilização" (2006, p. 82). Conforme o linguista, a relação do sujeito falante com a língua mostra os caracteres linguísticos da enunciação. Para o autor, devemos considerar a enunciação "como o fato do locutor, que toma a língua por instrumento, e nos caracteres linguísticos que marcam esta relação" (BENVENISTE, 2006, p. 82). Flores (2013) afirma que o 
homem está na língua e estar na língua é a enunciação.

Assim, a enunciação inclui no seu escopo a língua e a fala, isto é, o ato que um sujeito realiza ao comunicar os seus pensamentos.

É a semantização da língua que está no centro deste aspecto da enunciação, e ela conduz à teoria do signo e à análise da significância (BENVENISTE, 2006, p. 83).

Segundo Benveniste (2006), há dois modos de significação da língua. $\mathrm{O}$ modo semiótico, que está organizado por relações paradigmáticas e internas à língua, em que cada signo é significativo em relação à sua diferença com os demais e o modo semântico que está organizado por operações sintagmáticas no nível da frase, através da colocação da língua em ação por um locutor.

O modo semiótico da língua está ligado ao sistema de signos cuja significação se estabelece intrassistema, mediante distinção. O modo semântico, por sua vez, está ligado à atividade do locutor e implica construção de referência e agenciamento sintagmático (FLORES et al., 2009, p. 207).

Para Benveniste, "dizer que a língua é feita de signos é dizer antes de tudo que o signo é a unidade semiótica" (2006, p. 224, grifo do autor). Enquanto isso, Trois informa que "o signo depende da consideração semiótica da língua” (2004, p. 36), e explica ao leitor que o signo é limitado pela significação, o conceito de significação subordina o de signo.

De acordo com Benveniste (2005, 2006), no semiótico, a forma diz respeito ao significante, entendido como $\mathrm{o}$ aspecto formal da entidade que chamamos de signo, e o sentido diz respeito às relações de oposições com os outros signos da língua, pois, no semiótico, ser distintivo e significativo é a mesma coisa. Já o modo semântico está relacionado à atividade do locutor e necessita a construção da referência no sintagma da língua. Assim, a semiótica constitui uma propriedade da língua e a semântica, uma propriedade do locutor.

Dessa maneira, podemos dizer que as noções de forma e sentido, anteriormente disjuntas (semiótico, para a forma dos signos e semântico, para o sentido das palavras na frase), emanam de um locutor e são efetuadas em uma instância de discurso, que atinge um ouvinte e suscita uma enunciação de retorno. É o sujeito que se encontra marcado na língua ao fazer referência a si e ao seu povo ao utilizar uma forma dialetal no seu discurso.

Trois argumenta que esse englobamento, proposto por Benveniste, do nível de significação é produzido pela articulação semântica,

[...] onde o sentido é definido pela mensagem, que é organizada pelas palavras que por sua vez, são determinadas pelo contexto de situação de discurso (TROIS, 2004, p. 36).

$\mathrm{O}$ autor acrescenta que é isso que possibilita o desenvolvimento teórico da categoria de pessoa e dos conceitos de intersubjetividade e de enunciação.

O indivíduo faz uso das palavras, sem parar para pensar nelas, sem ter a consciência do seu ato, de sua enunciação. De acordo com Benveniste (2005), ao tomar 
a língua, o homem apresenta-se como "eu", em sua individualidade, em oposição ao "tu", estabelecendo uma relação intersubjetiva em meio à sociedade.

Caem assim as velhas antinomias do 'eu' e do 'outro', do indivíduo e da sociedade. Dualidade que é ilegítimo e errôneo reduzir a um só termo original, que esse termo único seja $e u$, que deveria estar instalado na própria consciência para abrir-se então à do 'próximo', ou seja, ao contrário, a sociedade, que preexistiria como totalidade ao indivíduo e da qual este só se teria destacado à medida que adquirisse a consciência de si mesmo. É uma realidade dialética que englobe os dois termos e os defina pela relação mútua que se descobre o fundamento linguístico da subjetividade (BENVENISTE, 2005, p. 287).

Através da relação de intersubjetividade que ocorre na estrutura do diálogo, percebemos a subjetividade do sujeito falante, ou seja, a subjetividade ocorre quando o locutor se apresenta como sujeito:

Uma dialética singular é a mola da subjetividade. A língua provê os falantes de um mesmo sistema de referências pessoais de que cada um se apropria pelo ato da linguagem e que, em cada instância de seu emprego, assim que é assumido por seu enunciador, se torna único e sem igual, não podendo realizar-se duas vezes da mesma maneira (BENVENISTE, 2006, p. 69).

O autor, nessa perspectiva, informa que o locutor se apropria do aparelho formal da língua e enuncia sua posição de locutor por meio de índices específicos, ${ }^{1}$ de um lado, e por meio de procedimentos acessórios, ${ }^{2}$ de outro. Benveniste esclarece que: "[...] o ato individual pelo qual se utiliza a língua introduz em primeiro lugar o locutor como parâmetro nas con- dições necessárias da enunciação" (2006, p. 83-84). Assim, antes da enunciação, a língua emana de um locutor e é efetuada em uma instância de discurso, que atinge um ouvinte e suscita outra enunciação de retorno.

Mais adiante, Benveniste (2006) explica que, a partir do momento que ele se declara locutor e assume a língua, automaticamente, insere o outro diante de si, qualquer que seja o grau de presença que ele atribua a esse outro.

Ao enunciar, o indivíduo não pode voltar a falar do mesmo jeito que acabou de proferir o enunciado, pois as funções enunciativas são irrepetíveis. Na subjetividade, o que vale é o tempo presente, pois o presente mostra a intenção do sujeito falante: "o presente formal não faz se não explicitar o presente inerente à enunciação, que se renova a cada produção de discurso" (BENVENISTE, 2006, p. 86), ou seja, é na enunciação que o presente do próprio ser se delimita, por referência interna, entre o que vai se tornar presente e o que não o é mais.

Logo, "cada enunciação é um ato que serve o propósito direto de unir o ouvinte ao locutor por algum sentimento, social ou de outro tipo" (BENVENISTE, 2006, p. 90), pois a linguagem, nessa função, age não como um instrumento de reflexão, mas como um modo de ação.

Dessa maneira, podemos verificar que a enunciação é um evento único, que não se repete e que está repleto de significados, isto é, a enunciação possui valores semióticos e semânticos. Para 
analisarmos o sentido semântico e semiótico do enunciado, devemos levar em consideração o contexto da interação, do diálogo, da enunciação.

\section{Linguagem e identidade cultural}

Língua e cultura possuem símbolos específicos pelos quais cada sociedade se identifica e diverge entre si. No entanto, a linguagem é o elo que une o homem à língua e à cultura. Benveniste, nesse ínterim, define a linguagem da seguinte forma:

\begin{abstract}
A linguagem é para o homem um meio, na verdade, o único meio de atingir o outro homem, de lhe transmitir e de receber dele uma mensagem. Consequentemente, a linguagem exige e pressupõe o outro. A partir deste momento, a sociedade é dada com a linguagem. Por sua vez, a sociedade só se sustenta pelo uso comum de signos de comunicação. A partir deste momento, a linguagem é dada com a sociedade. Assim, cada uma destas duas entidades, linguagem e sociedade, implica a outra (2006, p. 93).
\end{abstract}

Conforme Benveniste, "é na linguagem e pela linguagem que o homem se constitui como sujeito; porque só a linguagem fundamenta na realidade, na sua realidade que é a do ser, o conceito de ego" (2005, p. 286). Flores faz algumas discussões que derivam dessa passagem e explica que talvez não fosse absurdo considerar que: "quando Benveniste utiliza a construção pela linguagem, esteja pensando em língua. Nesse caso, poder-se-ia concluir que o homem se constitui sujeito na linguagem e pela língua" (2013, p. 98, grifo do autor).

O contato com pessoas de outras localidades em viagens de lazer, assim como o acesso à escola e ao trabalho, contribui para que mudanças ocorram no sujeito. A linguagem tem um papel importante, uma vez que confere ao indivíduo uma identidade, fazendo com que seja possível identificarmos a sua procedência (se é recifense, soteropolitano, cearense, alagoano, etc.), o grupo ao qual o indivíduo faz parte, ou seja, a classe social, a faixa etária, o nível de escolaridade e o sexo.

Destarte, a linguagem tem como função reconhecer a pessoa como sujeito através de suas marcas linguísticas e enunciativas. De acordo com Benveniste (2006), essa função da linguagem de constituir a pessoa como sujeito falante é o fator diferencial, visto que esse sujeito é marcado pela linguagem.

Os aspectos socioculturais e históricos influenciam a construção cultural de uma determinada região, visto que a língua utilizada por uma região específica dá a ela características próprias, facilitando a identificação do sujeito falante. De modo que a língua, por ser social, possui aspectos socioculturais, pelos quais é influenciada.

A esse respeito, Preti, referente à língua falada, informa que ela representa "uma das mais imediatas marcas de identidade social [...] e a fala se incorpora à identidade das pessoas, trazendo-lhes maior ou menor prestígio, no contexto social em que se envolvem" (2003, p. 49). 
Isto é, a identidade de um indivíduo vai depender do meio em que ele vive e com quais pessoas ele se relaciona. A interação social desse sujeito será, portanto, um aspecto importante na comunicação.

O modo de falar representa a maneira de pensar de cada grupo e as palavras utilizadas por esses grupos estão relacionadas à realidade de cada região. Sendo assim, a maneira de falar mostra a cultura na qual aquele indivíduo está inserido. Para Carvalho, a cultura é:

transmitida pela língua, sendo também seu resultado, o meio para operar e a condição da subsistência dessa cultura. [...] as diferenças culturais [...] podem ser regionais e até grupais $(2014$, p. 38-39).

A presença de índices carregados de cultura na fala do indivíduo pode mostrar a sua origem.

Em outras palavras, o indivíduo pode agir, atribuindo maior ênfase ao fato de ser jovem, ou de ser feminino ou pertencer à classe média (PAIM, 2013, p. 93).

Pertencer a um grupo social está relacionado ao conhecimento que os indivíduos têm das convenções locais, que servem para construir as identidades através de exibições de atos.

Assim, a identidade social é concebida como um significado social complexo que pode ser destilado do significado dos atos que a constitui (PAIM, 2013, p. 20).

Quando faz parte de uma determinada comunidade linguística, o indivíduo apresenta traços culturais daquele meio. Dessa forma, a cultura parece ter um fator determinante na identidade desses sujeitos falantes. A identidade cultural favorece as construções de visões de mundo, como defendido por Santana:

[...] quando essa identidade é linguisticamente construída e determinada, e muitos grupos humanos compartilham do mesmo grau de complexidade linguístico e consequentemente identitário, em face da cultura que integram, se estabelece um novo cenário (SANTANA, 2012, p. 51).

Sendo assim, entendemos que a identidade é algo construído no decorrer do tempo, ou seja, "ela permanece sempre incompleta, está sempre 'em processo', sempre 'sendo formada"' (HALL, 2015, p. 24). Dessa maneira, podemos deduzir que a identidade cultural está relacionada ao sujeito que reside em determinada região, neste estudo, em Salvador ou Recife, pois esse indivíduo está sempre em processo de formação, interagindo com o meio em que vive para sobreviver e formar laços que são fortalecidos através da língua, com os seus descendentes.

Concernente à língua, Benveniste (2006, p. 94) explica que ela é o espelho da sociedade, refletindo na estrutura social suas particularidades e variações. $\mathrm{O}$ autor ainda afirma que a língua é uma identidade em meio às diversidades individuais. Consequentemente, podemos inferir que o sujeito é marcado na linguagem através da língua e das expressões linguísticas que usa, e isso inclui o dialeto:

Tudo que dizemos tem um 'antes' e um 'depois' - uma margem' na qual outras pessoas podem escrever. O significado é inerentemente instável: ele procura o fechamento (a identidade), mas ele é constantemente perturbado (pela diferença). Ele está constantemente escapulindo de nós (HALL, 2015, p. 26). 
Quando consideramos o princípio de que é possível encontrar a identidade cultural nos traços linguísticos do falante, é porque verificamos que os traços linguísticos formam a identidade, e que são esses mesmos traços que marcam $o$ sujeito na linguagem. Por isso, propomo-nos a examinar as marcas do sujeito na língua, a partir dos verbos e das expressões verbais dialetais, relacionando o sentido definido de verbos e expressões verbais como índice cultural.

Benveniste (2006) afirma ser a enunciação o ato individual de colocar a língua em funcionamento. Esse aspecto aproxima, em nossas discussões, a afirmação do linguista à identidade cultural, pois o homem é um ser que vive em sociedade e, ao enunciar, pode utilizar-se de marcas linguísticas características de sua região. Dessa forma, ao considerar a possibilidade de o sujeito enunciar-se ao se apropriar do dialeto e utilizá-lo, percebemos a identidade cultural do sujeito falante, tendo em vista a relação estabelecida entre a língua e o sujeito na enunciação.

Benveniste menciona, ainda, que a sociedade é dada com a linguagem. "Assim, cada uma destas duas entidades, linguagem e sociedade, implica a outra" (2006, p. 93). Um exemplo disso são os sotaques, a variação linguística que marca o sujeito no discurso e indica a sua origem.

Percebemos que o sujeito traz na sua fala a identidade cultural. Por meio das marcas linguísticas, o sujeito se estabelece e se constitui na relação com o outro e com a língua, revelando, assim, a sua identidade cultural através da língua. Em termos teóricos, podemos dizer que a identidade cultural pertence à esfera do discurso.

Desse modo, a função identitária mostra o discurso sobre a cultura e a identidade cultural do falante, ou seja, "a ideia de identidade cultural revela um construto de práticas históricas e conjunção/dispersão de discursos sobre a cultura e sobre a identidade" (FREITAS, 2010, p. 322). É o sujeito que se encontra marcado na língua ao fazer referência a si e ao seu povo ao utilizar uma forma dialetal no seu discurso.

Gandini (2007, p. 54), tratando da relação discurso e cultura, explica que nem sempre a expressão cultural dialoga de modo consensual, às vezes é também conflituoso. Para o autor,

[...] a origem da referência cultural faz menção 'a pelo menos três elementos históricos que instituem a vida social: experiência/ sobrevivência, imitação e imaginação. Essas três dimensões não se processam de modo isolado, mas cruzam e dialogam, de forma complementar ou mesmo contraditória' (GANDINI, 2007, p. 54).

Dessa maneira, a identidade cultural vai se firmando com suas características próprias e definindo o povo. Aidentidade cultural expõe o sujeito que se encontra marcado na língua ao fazer referência a si e ao seu povo quando utiliza uma forma dialetal no seu discurso. Ou seja, é através das marcas enunciativas que é possível reconhecer a identidade do sujeito falante. 


\section{Procedimentos metodológicos e análise}

A metodologia usada neste trabalho foi baseada em uma pesquisa de campo do tipo estudo de caso, realizada nas cidades de Recife e Salvador, na qual discutimos a relação de sentido e as possíveis marcas do sujeito encontradas no discurso de indivíduos entrevistados em escolas, igrejas, shoppings, bibliotecas, feiras e estabelecimentos comerciais. $\mathrm{O}$ intuito era compor o perfil dos sujeitos, baseando-se nas orientações de Cardoso (2010) para a construção do Atlas Linguístico do Brasil (ALIB), ${ }^{5}$ fundamentadas em um tripé básico: a rede de pontos (a área a ser submetida à investigação dialetal), os informantes e os questionários, que podem ser adaptados de acordo com as diferentes perspectivas teóricas e os objetivos da pesquisa.

Optamos por catalogar respostas com o registro de verbos proferidos em Salvador e em Recife por falantes de dois grupos (grupo 1: recifenses e grupo 2: soteropolitanos), com o intuito de verificar a relação cultural e de sentido dos verbos nos sujeitos falantes entrevistados, uma vez que o sujeito marca a forma que for seu lugar na cultura ou no próprio discurso sobre a cultura (FREITAS, 2010).

Seguindo a proposta do ALIB, utilizamos o questionário com transcrição grafemática e direta, que foram efetuadas no ato da entrevista, na qual solicitamos que os sujeitos respondessem questões relativas à classe gramatical dos verbos, para trazer os verbos como indicadores de subjetividade. Objetivamos, com isso, investigar as possíveis diferenças de sentido entre os verbos dos recifenses e dos soteropolitanos, demonstrando uma provável relação subjetiva estabelecida no uso dos verbos em cada região campo da pesquisa, pois os verbos, para Benveniste, estão relacionados "à dêixis: formas disponíveis na língua cujo emprego remete à enunciação" (2005, p. 288).

Esclarecemos que a escolha do perfil e da faixa etária dos informantes segue as normas adotadas pelo ALIB, que, conforme Cardoso (2010), já estabeleceu que não há mudanças linguísticas significativas na faixa etária entre 30 e 50 anos.

Nas entrevistas, utilizamos um questionário adaptado de acordo com a realidade de cada região investigada (Recife e Salvador) referente aos verbos. Para isso, também nos espelhamos no Questionário Morfossintático (QMS) do ALiB.

Foram entrevistados quarenta informantes: vinte sujeitos entrevistados em cada capital, distribuídos em duas faixas etárias: de 18 a 30 anos e de 50 a 65 anos. Além da seleção da faixa etária, os entrevistados foram selecionados por escolaridade, nas seguintes divisões: até o $5^{\circ}$ ano ou curso superior completo

Antes das entrevistas, todos os informantes assinaram o termo de consentimento livre e esclarecido. Depois, foram preenchidas as fichas do informante conforme modelo do ALIB, disponibilizado por Cardoso (2010). 
Em Recife, foram entrevistados dez mulheres e dez homens, sendo nove mulheres com ensino superior e uma com até o $5^{\circ}$ ano do ensino fundamental. Dessas, seis mulheres na faixa etária de 18 a 30 anos e quatro mulheres na faixa etária de 50 a 65 anos. Foram entrevistados dez homens com nível superior, sendo que um homem pertence à faixa etária de 50 a 65 anos e nove homens pertencem à faixa etária de 18 a 30 anos.

Em Salvador, foram entrevistados quinze mulheres e cinco homens, sendo sete mulheres com ensino superior e oito mulheres com até o $5^{\circ}$ ano do ensino fundamental, cinco mulheres na faixa etária de 50 a 65 anos e dez na faixa etária de 18 a 30 anos. Referente aos homens, foram entrevistados três com ensino superior, sendo dois homens na faixa etária de 18 a 30 anos e um homem na faixa etária de 50 a 65 anos; e dois homens com até o $5^{\mathrm{o}}$ ano do ensino fundamental, com a faixa etária de 18 a 30 anos.

Em cada ponto da pesquisa (Recife e Salvador), consideramos as dimensões: diagenérica (homens e mulheres), diageracional (18 a 30 anos e 50 a 65 anos) e diastrática (até o $5^{\circ}$ ano do ensino fundamental e com curso superior completo).

Pela rigidez do critério definido pelo ALiB para a seleção dos indivíduos entrevistados, o quantitativo de homens e mulheres entrevistados não foi igual nas duas cidades, haja vista, principalmente, a dificuldade em encontrar pessoas que tenham cursado apenas até o $5^{\mathrm{o}}$ ano do ensino fundamental. Fato esse resultan- te das mudanças na administração pública brasileira voltadas para a educação nos últimos dez anos.

Todos os informantes entrevistados são nascidos nos dois pontos de inquéritos e seus pais também são nativos, tendo saído poucas vezes da localidade. Além disso, os sujeitos entrevistados não apresentaram problemas articulatórios (gagueira, falta de dentes, desvios fonéticos e fonológicos), que poderiam dificultar a coleta dos dados.

Vale ressaltar que, quando o pesquisador se detém a analisar o português falado em cada região do Brasil, pode verificar que o falante pode criar, durante a conversa informal, novas maneiras de falar e de referir-se à determinada questão, provocando movimentos singulares de transposição de sentido na linguagem. $\mathrm{O}$ fato é que a linguagem confere ao homem e à comunidade linguística da qual ele faz parte características peculiares de observar o mundo ao seu redor. Cada comunidade linguística faz sua leitura de mundo, que é influenciada pelos aspectos socioculturais e históricos.

Por isso, concordamos com Benveniste: "língua e sociedade não se concebem uma sem a outra" (2005, p. 31), ou seja, poderíamos deduzir que, ao mencionar "língua e sociedade", o autor aponta para cultura.

Para compreender melhor as nuances que permeiam a fala dos dois pontos de inquérito, as cidades de Salvador e Recife, que, embora próximas geograficamente, apresentam características sociocultu- 
rais distintas, apresentamos, a seguir, alguns dados que confirmam o sentido e as marcas do sujeito ao utilizar os verbos dialetais face à variação dos itens lexicais.

Questão 1: Como se chama a ação do homem (ou mulher) que pega muitas mulheres (ou homens)?

Gráfico 1 - Designações para 'nigrinhar/galinhar'

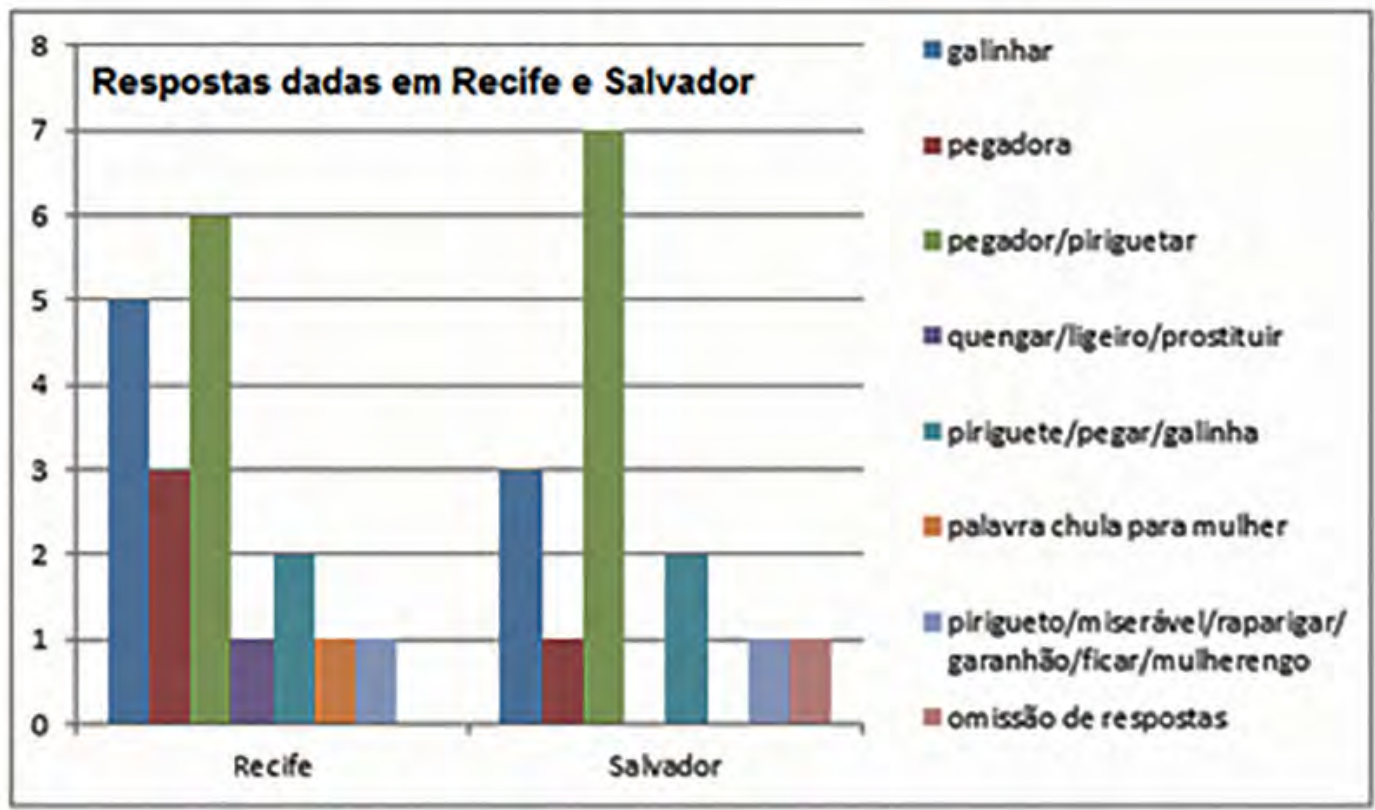

Fonte: elaboração das autoras.

As respostas para a questão 1 que os falantes forneceram foram variadas. Em Recife, encontramos: 'galinhar', 'ligeiro', 'pegador', 'puta', 'quengar', 'pegadora', 'ficar', 'garanhão', 'prostituir' e 'pegar'. Em Salvador, percebemos também muitos dialetos para caracterizar a ação do homem ou da mulher que pega muitas mulheres ou homens: 'pegador', 'pegadora', 'galinha', 'periguetar', 'galinhar', 'piriguete', 'pirigueto', 'miserável' e 'mulherengo'.

Verificamos que, dependendo da idade, do gênero e da profissão, a variação no uso dos verbos foi mais acentuada. Constatamos também que muitos não sabem o que é um verbo, pois indicaram palavras que não pertencem a essa classe gramatical, mas que indicam aquele ato de 'pegar muitas pessoas'. Para Bernardino, 'quengar' significa "procurar parceiro sexual" (2002, p. 162), para Lariú (1991, 2013, não paginado) 'piriguete' significa "mulher fácil, que está a fim de qualquer coisa; cerveja em lata pequena, à venda nos estádios e nas festas de rua". Outra curiosidade observada foi a forma 
masculina dada para designar a palavra 'piriguete', ou seja, o homem que pega muitas mulheres em Salvador também pode ser chamado de 'pirigueto'.

Nas gramáticas normativas da língua portuguesa, os substantivos masculinos terminados em e trocam o e por a, em sua versão feminina. Mas, no caso da única resposta proferida por uma entrevistada com nível superior, o dialeto 'piriguete' assumiu a forma feminina, enquanto a masculina acresceu $o$ artigo masculino o, transformando-se em 'pirigueto'. O sujeito, ao enunciar-se, corrompeu a norma culta da língua, talvez influenciado por uma questão cultural: 'piriguete' está relacionado à prostituição, que, no Brasil, é considerada uma profissão feminina.

Os falantes têm o hábito de designar a pessoa que se prostitui como 'prostituta', mas não designam 'prostituto' para se referir ao homem que se prostitui. Para nomear o homem que mantém relações sexuais em troca de dinheiro, o termo usado é 'garoto de programa'. Assim, constatamos que a forma 'garoto de programa' é mais polida do que a forma prostituta. O vocábulo 'prostituta' transforma a mulher em objeto. De outro modo, o vocábulo 'garoto de programa' torna mais suave a expressão. A mulher vista como profissional do sexo, conforme o Dicionário Houaiss, é a "mulher que ganha dinheiro para manter relações sexuais, meretriz" (HOUAISS; VILLAR, 2009, p. 611).

Destacamos que nenhum entrevistado mencionou o vocábulo 'prostituto', fazendo associação ao feminino 'prostituta', mas foi utilizado 'pirigueto'. A palavra 'piriguete' é uma gíria, ${ }^{3}$ e também podemos considerá-la como um neologismo, pois a lexia é utilizada pelas pessoas jovens e chama bastante atenção das pessoas mais velhas, que acabam inserindo-a em suas falas, o novo chama atenção.

Conforme Messias (2013), a lexia 'piriguete' surgiu nas favelas de Salvador e a mesma é tida como uma gíria marginal. Segundo o autor, o item lexical 'piriguete' é um neologismo formado da junção das palavras: 'perigosa e girl'. De acordo com Messias, 'perigosa' transformou-se em 'pirigosa' e, para não ficar estranha a pronúncia, as pessoas passaram a utilizar o guete, ficando 'piriguete'.

Ainda, se levarmos em consideração que o item lexical 'piriguete' surgiu nas favelas de Salvador, podemos inferir a criação da lexia pela junção de: perigo + gueto, ou seja, uma composição por aglutinação, pois o significado de 'perigo' pode ser uma gíria: "sem dinheiro, em situação de risco perigar" (HOUAISS; VILLAR, 2009, p. 387). Já a lexia 'gueto' significa: "bairro onde, por imposição econômica e/ou racial, são confinadas certas minorias" (HOUAISS; VILLAR, 2009, p. 387).

Além disso, verificamos que alguns indivíduos mais velhos analisam o item lexical novo antes de usá-lo, na tentativa de encontrar um sentido que justifique seu uso. Esses sujeitos preferem usar o termo arcaico 'prostituir', conforme 
constatado na fala de VML, 55 anos, sexo feminino e com ensino superior, um termo polido em comparação ao léxico 'piriguete'.

Os itens lexicais 'pegador' e 'pegadora' também são considerados como neologismos e gírias. Além disso, no item lexical 'pegador', constatamos a enunciação do falante e uma transferência de significado, pois 'pegador' pode ser aquele objeto que usamos para pendurar a roupa no varal. Para Navarro (2013, p. 516), 'pegador' significa armador. Contudo, define 'armador' como:

[...] armador de rede, pegador, pegadouro, peça de madeira ou de ferro (gancho) em que se prende, numa parede, por tal ou outra superfície firme, o punho da rede de dormir (2013, p. 68).

Nos dicionários de Houaiss e Villar (2009), de Bernardino (2002) e de Lariú (1991, 2013), não encontramos o significado da palavra 'pegador'. Também analisamos o modo feminino da forma 'pegador': a mulher que pega muitos homens pode ser chamada de 'pegadora' na cidade baiana.

Diferentemente das regras gramaticais que foram aplicadas no caso 'pireguete/pirigueto', em 'pegador', identificamos que houve uma derivação imprópria do verbo 'pegar', que foi transformado em um substantivo. Outro fato a ser observado é a resposta dada por um recifense, RAFS, 27 anos, sexo masculino e com ensino superior, que considerou o homem como 'pegador' e não informou o significado para a mulher, pois disse que a palavra é chula e não poderia informar o sentido para a pesquisadora. Dessa forma, constatamos uma forma de tabu linguístico, aspecto bem discutido pela semântica histórica. Para Guérios, “o tabu linguístico é a proibição de dizer qualquer expressão imoral ou grosseira" $(1979$, p. 5). O fato de o sujeito falante estar sendo entrevistado por uma mulher o deixou 'constrangido' para denominar a ação da mulher que pega muitos homens. Aqui, verificamos a marca cultural do homem nordestino, recifense, poderíamos dizer 'machista', preocupado com o uso de determinada palavra diante de uma mulher que estava entrevistando-o.

Identificamos, também, as marcas culturais e enunciativas do sujeito ao usar a designação: 'miserável'. Apesar de essa palavra não ser um verbo, em Salvador, significa o homem que pega muitas mulheres, ou seja, é um regionalismo. O dialeto 'miserável' é preferível para o baiano, pois, em Salvador, é comum as pessoas falarem 'miserável, miséria'. No dicionário de Baianês (1991, 2013, não paginado), encontramos: 'misera/ miserê', "vocativo geral ('Digaê misera! Fala, miserê!')"; 'miseravão' "cara retado, ${ }^{4}$ alguém bom em alguma coisa, que resolve qualquer parada (Feminino; miseravona)". Provavelmente, para RWL, 25 anos, o valor semântico do item lexical 'miserável' é: o cara retado que pega muitas mulheres, ou seja, significa ser homem bom de papo, sedutor.

As derivações de 'galinhar e garanhão' vêm da palavra 'galinha'. Em Houaiss e Villar, 'galinha' é: "fêmea do galo, 
que $(m)$ varia de parceiros amorosos com frequência" (2009, p. 369). Já 'garanhão' é definido como: "(cavalo) destinado à reprodução; (homem) mulherengo" (2009, p. 370). Podemos relacionar o sentido usado da palavra 'garanhão' como índice de identificação cultural, pois esse vocábulo caracteriza o homem: 'ligeiro, miserável, pegador', e foi usado por vários sujeitos falantes para caracterizar o 'homem mulherengo'.

A resposta dada pela informante recifense NR, 24 anos, chama a ação de 'pegar' muitos homens de: 'quengar'. Esse item lexical pode ser considerado em desuso, pois só é falado por pessoas mais velhas. Isso talvez justifique o fato de essa jovem ter contato com pessoas da tipificação etária de mais idade, que utilizam esse item lexical. No dicionário de pernambuquês, 'quengar' significa "buscar parceiro sexual” (2002, p. 162). No dicionário de baianês (1991, 2013, não paginado), 'quengar' tem três formas de utilização: "mulher feia; caso de alguém, ‘puta”. Já no dicionário do Nordeste, 'quenga' é "prostituta da zona do porto, 'fubana', 'penica', do baixo meretrício" (2013, p. 555).

De acordo com Castro (2005), a palavra 'quenga' tem origem na Bahia, significando: guisado de galinha e quiabo, mas também é um verbete da linguagem popular regional brasileira, que pode significar: "cuia, vasilha feita da metade da casca do coco; o conteúdo da vasilha" (2005, p. 320).
O item lexical 'quengada', conforme Castro (2005), refere-se ao grupo de prostitutas, estruturando-se por: quenga +0 sufixo -ada. Através da etimologia e da aplicação histórica, podemos compreender o uso do termo. Segundo Mendonça:

Língua e raça formam dois elementos que têm evolução paralela a ponto de serem muitas vezes confundidos. Como o negro fundiu com o português e do consórcio resultou o mestiço, pareceria lógico que este mestiço falasse um dialeto crioulo. [...] O negro influenciou sensivelmente a nossa língua popular. Um contato prolongado de duas línguas sempre produz em ambas fenômenos de osmose. Ao lado da contribuição genérica e imprecisa que deu o africano para o alongamento das pretônicas e a elocução clara e arrastada, deixou sinais bem seus nos dialetos (1973, p. 60-61).

Um aspecto que deve ser destacado é que o item lexical 'nigrinhar' não foi mencionado pelos soteropolitanos. Podemos afirmar que essa lexia está em processo de mudança em Salvador e que, pela força do intercurso mencionada por Saussure ([1916] 2006), perdeu o seu espaço para o dialeto 'piriguete'. Para Castro, 'nigrinha' significa: "mulher desvergonhada, sirigaita, alguém de baixo nível, de mau comportamento. Ver nigrinhagem. Cf. Port. negrinha" (2005, p. 297). A linguista explica que 'nigrinhagem' é uma palavra da Bahia que representa "safadeza, atitude de nigrinha".

Preti, referente à língua falada, informa que essa representa:

[..] uma das mais imediatas marcas de identidade social [...] a fala se incorpora à identidade das pessoas, trazendo-lhes maior ou menor prestígio, no contexto social em que se envolvem (2003, p. 49). 
Isto é, a identidade de um indivíduo vai depender do meio em que ele vive e com quais pessoas ele se relaciona, a interação social do sujeito será um aspecto importante na hora da comunicação.

$\mathrm{O}$ modo de falar representa a maneira de pensar de cada grupo e as palavras utilizadas por esses grupos estão relacionadas à realidade de cada região. Sendo assim, a maneira de falar mostra a cultura na qual o indivíduo está inserido. Para Carvalho, a cultura é: "transmitida pela língua, sendo também seu resultado, o meio para operar e a condição da subsistência dessa cultura. [...] as diferenças culturais [...] podem ser regionais e até grupais" (2014, p. 38-39).

A presença de índices carregados de cultura na fala do indivíduo mostra a sua origem. Além disso, a intenção comunicativa dependerá de aspectos relativos à faixa etária, à classe social, ao sexo e à profissão do indivíduo. A marca cultural do sujeito falante, o espaço, o tempo e a pessoa são os itens que irão definir o sentido do item lexical usado em um determinado contexto enunciativo. De acordo com Cançado:

O sentido é o modo no qual a referência é apresentada, ou seja, o modo como uma expressão linguística nos apresenta a entidade que ela nomeia [...] o sentido tem relação direta com o conceito que temos sobre as expressões linguísticas, podemos acrescentar, ainda, que o sentido refere-se ao sistema de relações linguísticas que um item lexical contrai com outros itens lexicais, ou que o sentido de uma expressão é o lugar dessa expressão em um sistema de relações semânticas com outras expressões da língua (2005, p. 83).
Forma e sentido estão profundamente ligados. Um não anda sem o outro, mas essa ligação não pode ser inteiramente contingente. Se nos preocuparmos em descrever atentamente as formas, descobrimos que é o sentido que dá a razão de suas diferenças, até mesmo de suas anomalias. Os sujeitos entrevistados posicionaram-se de diferentes maneiras, ratificando a visão enunciativa de que 0 sentido pode ser semântico e semiótico.

De acordo com as análises das respostas dos informantes recifenses e soteropolitanos, percebemos índices enunciativos dos sujeitos no sentido dado aos signos dialetais. Para que um signo exista, é necessário que ele seja aceito e que se relacione, de uma maneira ou de outra, com os demais signos. Segundo Benveniste (2006), significar é ter sentido, nada mais. É no uso da língua que um signo tem existência; o que não é usado não é signo; fora do uso, o signo não existe. A depender de quem seja o sujeito falante, o significado será visto no ato da enunciação. Para Cruz, Menezes e Pinto, "as manifestações culturais são representativas da voz social" (2008, p. 4). Em Recife e Salvador, é perceptível que as manifestações culturais mostram as interações e oposições no tempo e no espaço. Essa força identitária valoriza e fortalece os dialetos de cada localidade. 
Questão 2: Como se chama a ação de pedir desconto sempre que vai comprar algo à vista ou que já esteja com desconto?

Gráfico 2 - Designações para 'pechinchar'

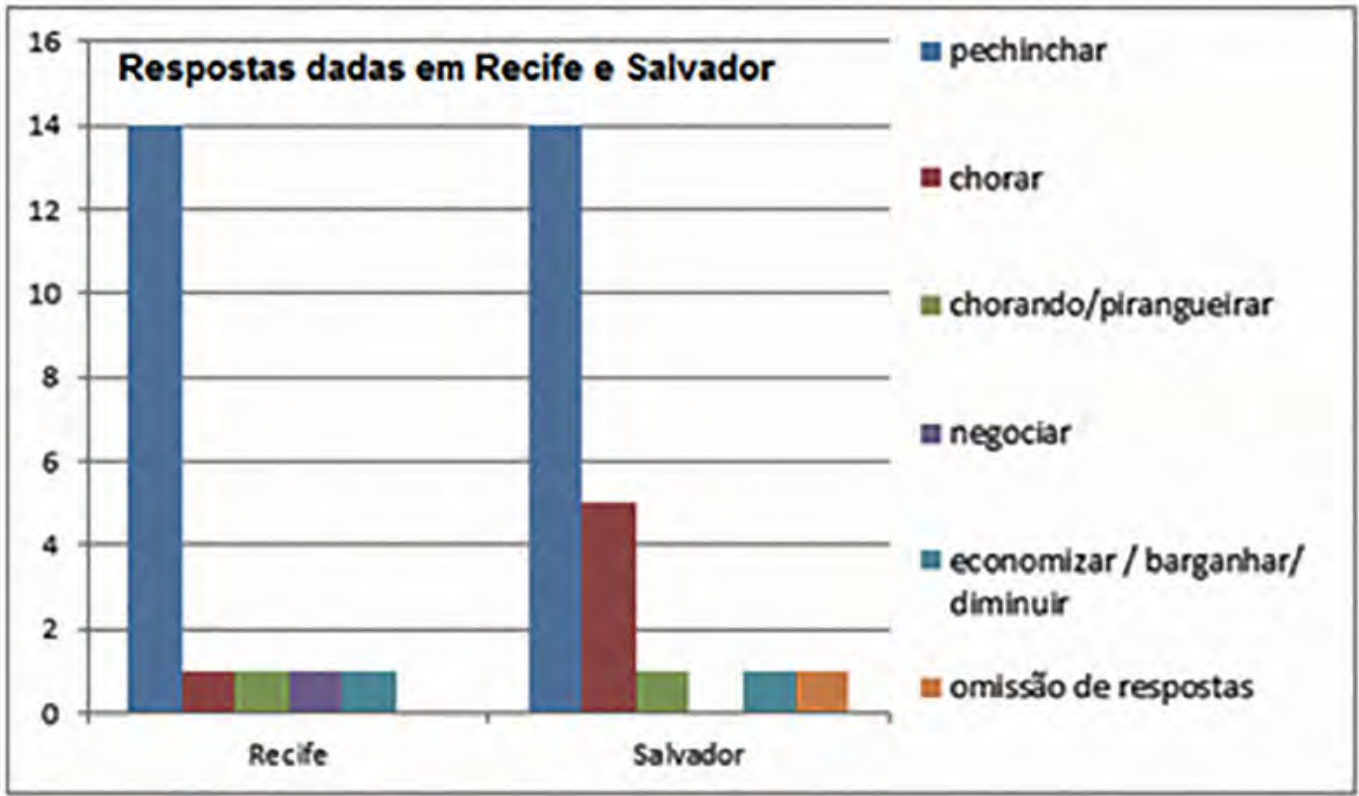

Fonte: elaboração das autoras.

Os itens lexicais apontados pelos recifenses para a questão 2 foram: negociar, pechinchar, pirangueirar, diminuir, chorar. Em Salvador, as respostas foram: chorar, pechinchar, barganhar, pedir um abatimento.

De acordo com Houaiss e Villar, o termo 'pechinchar' significa: "pedir redução do (de) preço; barganhar" (2009, p. 565), e 'barganhar' é: "pedir redução do (de) preço; pechinchar" (2009, p. 90). Já o vocábulo 'negociar' é: "fazer transação comercial de (mercadoria e serviço) [com pessoa, empresa]; comerciar" (2009, p. 525). A palavra 'diminuir' representa: "reduzir(-se) a uma quantidade, dimen- são ou intensidade menor; reduzir o mérito, (valor)" (2009, p. 251). E 'chorar' é: "derramar lágrimas, servir choro, dose; queixar-se de, geralmente com lágrimas, lastimar; pedir redução de preço (de); pechinchar" (2009, p. 156).

$\mathrm{Na}$ visão dos entrevistados, parece que 'pechinchar, barganhar, negociar, diminuir e chorar' são sinônimos. Mas é conveniente analisar o duplo sentido da palavra 'chorar', pois, além de ser usada como 'pechinchar', pode significar 'derramar lágrimas, servir choro'. O sentido de 'chorar' só vai ser constatado quando o sujeito apropriar-se da língua e expor a sua enunciação. Isso vai depender de seu 
conhecimento de mundo e da cultura na qual ele está inserido. Segundo Benveniste, "[...] a cultura define-se como um conjunto muito complexo de representações, organizadas por um código de relações de valores: tradições, [...] Pela língua o homem assimila a cultura, a perpetua ou a transforma" (2005, p. 32).

Com os verbos citados, podemos examinar as marcas do sujeito na língua. $\mathrm{O}$ verbo, segundo Azeredo, "é a espécie de palavra que ocorre nos enunciados sob distintas formas (vocábulos morfossintáticos) para a expressão das categorias de tempo, aspecto, modo, número e pessoa" (2008, p. 180). Além disso, em todas as suas categorias (aspecto, tempo, pessoa, gênero), o verbo apresenta um modo de significação subjetivo ou um modo de significação objetivo, sendo parte de um discurso contendo eu ou contendo ele, respectivamente. Além da categoria de pessoa, as categorias de tempo e espaço partilham do mesmo status linguístico e figuram como pertencentes ao discurso.

'Pirangueirar' é uma derivação sufixal, pois ocorreu um acréscimo do sufixo -'ueirar' à palavra 'pirangar', que só é reconhecida pelo dicionário de pernambuquês. Bernardino explica que 'pirangar' significa: "mendigar, pedir emprestado; pedir desconto" (2002, p. 154). O item lexical 'pirangar' é marca dialetal recifense, uma vez que nenhum soteropolitano mencionou essa forma para se referir à ação da pessoa que pede desconto.

De outro modo, em Salvador, foi detectada a predominância do verbo 'pechin- char', seguido de 'chorar' e da derivação 'chorando'. Como foi mencionado anteriormente, só entenderemos o sentido de 'chorar' quando o sujeito apropriar-se da língua. É perceptível a derivação sufixal (-ando) da forma do verbo no gerúndio da palavra 'chorar'. A expressão 'pedir um abatimento' é um sinônimo de pedir um desconto, uma redução de valor.

\section{Considerações finais}

Na perspectiva enunciativa de Benveniste, investigamos os sentidos semântico e semiótico dos verbos nos dialetos soteropolitano e recifense. Essa relação foi possível, pois entendemos que a forma dialetal traz um sentido para aquele que fala. A noção de sentido, na teoria enunciativa de Benveniste, não pode ser entendida sem que seja relacionada à noção de forma, pois, segundo o autor, há na língua, duas maneiras de ser língua: no sentido e na forma, sendo essa a capacidade que tem o sistema de se dividir nas unidades da frase e aquele a capacidade das unidades de se integrar na frase.

Através dos verbos, examinamos as marcas do sujeito na língua. Constatamos que o verbo, em todas as suas categorias (aspecto, tempo, pessoa, gênero), apresenta um modo de significação subjetivo ou um modo de significação objetivo, quando faz parte de um discurso contendo eu ou contendo ele, respectivamente. Ou seja, além da categoria de pessoa, as categorias de tempo e espaço 
partilham do mesmo status linguístico e figuram como pertencentes ao discurso.

Verificamos o sentido da língua, considerando a forma dialetal e a identidade cultural, pois o sujeito revela-se e revela a sua identidade através da língua. Como percebemos, o sentido de um enunciado se estabelece em uma relação subjetiva entre os interlocutores dentro do contexto da ação comunicativa. A marca cultural do sujeito falante, somada aos aspectos dêiticos tratados por Benveniste (2005, 2006), o espaço, o tempo e a pessoa são os itens que definem o sentido do item lexical usado pelo sujeito em um determinado contexto enunciativo.

Quando consideramos esse princípio, encontramos a identidade cultural nos traços linguísticos do falante. Os traços linguísticos formam a identidade e marcam o sujeito na linguagem. A sociedade é suscetível ao modo como o sujeito se estabelece e se constitui na relação com o outro e com a língua. Dessa maneira, em nossas discussões, constatamos que o sujeito (re)afirma sua identidade cultural através da língua em uso. Quando nos referimos aos sujeitos falantes de duas regiões distintas como Recife e Salvador, percebemos que o dialeto marca o sujeito e assume o sentido de formador de identidade.

Entretanto, o que dificulta o entendimento de sentido de um item lexical é a pluralidade de significado que as formas adquirem no sintagma da língua no momento da fala. Além disso, verificamos que a língua descreve, conceitua e interpreta a experiência de uma sociedade, isso assegura o seu caráter subjetivo e referencial na enunciação.

Após a análise dos resultados, comprovamos que as formas dialetais registradas pelos informantes de Recife e Salvador são dotadas de sentido, o que nos permite concluir que as relações de sentido perpassam por quem faz uso da linguagem e que a relação do sujeito com a língua é refletida pela questão da identidade do povo. A enunciação, entendida como a colocação da língua em funcionamento por um ato individual de utilização, possibilita que identifiquemos o dialeto como marca enunciativa do sujeito falante.

The man in the language: the dialect as an index of subjectivity and cultural identity

\section{Abstract}

The theory drawn in this work revolves around the enunciative axiom of Benveniste (2005, 2006, 2014): enunciation is to put the language into operation by an individual act of use. Based on a qualitative study of the case study, conducted in two Northeastern capitals, Recife and Salvador, based on the guidelines of Cardoso (2010) and the studies of Benveniste $(2005,2006)$, we identified signals that permeate the speech of two spaces but with different social and cultural characteristics at the same time. Our aim is to reveal that the enunciation has semiotic and seman- 
tic values, which mark the subject in the discourse, highlighting the dialect not only as a linguistic trait of a community but loaded with meaning for the users of the language, which at the same time reaffirms its identity cultural.

Keywords: Enunciation. Form. Cultural identity. Sense. Subjectivity.

\section{Notas}

1 Segundo Flores, índices específicos são: "recursos linguísticos, previstos no aparelho formal da língua, cuja função é colocar o locutor em relação constante e necessária com sua enunciação e que permitem ao locutor enunciar a sua posição de locutor. São as categorias de pessoa, tempo e espaço" (2013, p. 177).

2 Para Flores, procedimentos acessórios são: "recursos linguísticos, previstos no aparelho formal da língua, cuja função é colocar o locutor em relação constante e necessária com a enunciação. São todos os mecanismos linguísticos que, embora não específicos, servem para o locutor enunciar a sua posição" (2013, p. 177).

3 Segundo Carvalho, a gíria é um neologismo e, em suas palavras, "para designar neologismos populares, a palavra mais abrangente é gíria" (2011, p. 51).

4 O soteropolitano fala retado e o recifense fala arretado, no sentido de coisa boa. Ex.: A casa é retada.

5 ALIB. Disponível em: <http://twiki.ufba.br/ twiki/bin/view/Alib/WebHome>. Acesso em: 24 out. 2015 .

\section{Referências}

AZEREDO, José Carlos de. Gramática Houaiss da Língua Portuguesa. São Paulo: Publifolha, 2008.

BENVENISTE, Émile. Problemas de linguística geral I. Trad. Maria da Glória Novak e Maria Luisa Neri. 5. ed. Campinas: Pontes, 2005.
. Problemas de linguística geral II. Trad. Eduardo Guimarães et al. 2. ed. Campinas: Pontes, 2006.

Últimas aulas no Collège de France. Trad. Daniel Costa da Silva et al. São Paulo: Editora Unesp, 2014.

BERNARDINO, Bertrando. Minidicionário de pernambuquês. 3. ed. Recife: Bagaço, 2002.

CANÇADO, Márcia. Manual de semântica: noções básicas e exercícios. Belo Horizonte: Editora UFMG, 2005.

CARDOSO, Suzana Alice. Geolinguística: tradição e modernidade. São Paulo: Parábola, 2010 .

CARVALHO, Nelly. O texto publicitário na sala de aula. São Paulo: Contexto, 2014.

Princípios básicos de lexicologia.

2. ed. Recife: Editora Universitária da UFPE, 2011.

CASTRO, Yeda Pessoa de. Falares africanos na Bahia: um vocabulário afro-brasileiro. 2. ed. Rio de Janeiro: Topbooks, 2005.

CRUZ, Mércia Socorro Ribeiro; MENEZES, Juliana Santos; PINTO, Odilon. Festas culturais: tradição, comidas e celebrações. In: EBECULT-FACOM/UFBA, 1, 2008. Anais... Salvador, BA: Editora da UFBA 2008. p. 1-36.

FLORES, Valdir do Nascimento et al. $D i$ cionário de linguística de enunciação. São Paulo: Contexto, 2009.

FLORES, Valdir do Nascimento. Introdução à teoria enunciativa de Benveniste. São Paulo: Parábola, 2013.

FREITAS, Luis Felipe Rhoden. Aidentidade cultural na interface com os estudos enunciativos e discursivos. In: SITED, 2010. Anais... Porto Alegre, RS, 2010. p. 322-330.

GANDINI, Sérgio Luiz. Cultura Popular. In: GADINI, Sérgio Luiz; WOITOWICZ, Karina Janz (Org.). Noções básicas de folkcomunicação: uma introdução aos principais termos, 
conceitos e expressões. Ponta Grossa: Editora UEPG, 2007. p. 54-58.

GUÉRIOS, Rosário Farâni Mansur. Tabus linguísticos. 2. ed. aum. São Paulo: Editora Nacional; Curitiba: Editora Universidade Federal do Paraná, 1979.

HALL, Stuart. A identidade cultural na pós-modernidade. Trad. Tomaz Tadeu da Silva e Guacira Lopes Louro. Rio de janeiro: Lamparina, 2015.

HOUAISS, Antônio; VILLAR, Mauro de Sales. Minidicionário Houaiss da língua portuguesa. 3. ed. rev. e aum. Rio de Janeiro: Objetiva, 2009.

LARIÚ, Nivaldo. Dicionário de baianês. Salvador: Copyright, 1991.

Dicionário de baianês. 5. ed. rev. e ampl. Salvador: Copyright, 2013.

MARQUES, Maria Helena Duarte. Iniciação à semântica. 7. ed. Rio de Janeiro: Jorge Zahar, 2011.

MENDONÇA, Renato. A influência a fricana no português do Brasil. 4. ed. Rio de Janeiro: Civilização Brasileira, 1973.

MESSIAS, Aderlan. Desenrola a língua. $R e$ vista A, Oeste da Bahia: Ouza Editora, ago. 2013. Disponível em: <http://www.revistaa. net/colunistas/aderlan-desenrola-lingua/ piriguete-e-ricardao-no-dicionario/\#.Vu7EMnp1xOY>. Acesso em: 25 jan. 2016.

NAVARRO, Fred. Dicionário do Nordeste. 2. ed. Recife: Cepe, 2013.

PAIM, Marcela Moura. Identidade social e variação em Salvador. In: LOPES, Norma da Silva; BULHÕES, Lígia Pellon de Lima; PARCERO, Lúcia Maria de Jesus (Org.). Salvador, sob o olhar da sociolinguística. Feira de Santana: UEFS Editora, 2013. p. 91-105.

PRETI, Dino. Léxico na língua oral e escrita. In: PRETI, Dino. Variação lexical e prestígio social das palavras. São Paulo: Humanitas/ FFLCH/USP, 2003.
SANTANA, Joelton Duarte de. Língua, cultura e identidade: a língua portuguesa como espaço simbólico de identificação no documentário: Língua - vidas em português. Revista Linha D’Água, São Paulo, v. 25, n. 1, p. 47-66, 2012.

SAUSSURE, Ferdinand de. Curso de Linguística Geral. São Paulo: Cultrix, 2006.

TROIS, João Fernando de Moraes. O "retorno a Saussure" de Benveniste: a língua como um sistema de enunciação. Letras de Hoje, Porto Alegre, v. 39, n. 4, p. 33-43, dez. 2004. 